JPE 11-4-2

\title{
Torque Density Improvement of Five-Phase PMSM Drive for Electric Vehicles Applications
}

\author{
Pinzhi Zhao ${ }^{\dagger}$ and Guijie Yang* \\ $\dagger^{*}$ Dept. of Electrical Engineering and Automation, Harbin Institute of Technology, Harbin, China
}

\begin{abstract}
In order to enhance torque density of five-phase permanent magnetic synchronous motor with third harmonic injection for electric vehicles (EVs) applications, optimum seeking method for injection ratio of third harmonic was proposed adopting theoretical derivation and finite element analysis method, under the constraint of same amplitude for current and air-gap flux. By five-dimension space vector decomposition, the mathematic model in two orthogonal space plane, $d_{1}-q_{1}$ and $d_{3}-q_{3}$, was deduced. And the corresponding dual-plane vector control method was accomplished to independently control fundamental and third harmonic currents in each vector plane. A five-phase PMSM prototype with quasi-trapezoidal flux pattern and its fivephase voltage source inverter were designed. Also, the dual-plane vector control was digitized in a single XC3S1200E FPGA. Simulation and experimental results prove that using the proposed optimum seeking method, the torque density of five-phase PMSM is enhanced by $20 \%$, without any increase of power converter capacity, machine size and iron core saturation.
\end{abstract}

Key Words: Dual-plane vector control, Finite element analysis, Five-phase PMSM, FPGA, Harmonic control, Multi-phase systems

\section{INTRODUCTION}

In recent decades, the development of next generation vehicles which are more efficient and have less air pollution is being carried out actively throughout the world. EV is a road vehicle which involves an electric propulsion system. With this broad definition in mind, EVs include battery electric vehicles (BEVs), hybrid electric vehicles (HEVs) and fuel-cell electric vehicles (FCVs) [1]-[3]. The electric motor propulsion system is the heart of the EVs, which consists of the electric motor, its power converter, and an electronic controller. The requirements for the EV motor drive include: large torque, high speed, high power density, quick response and good dependability [4].

Selection of right electric motor is of primary importance to EVs designer. Nowadays, three-phase induction motors and permanent magnet machines are more appropriate solutions due to their lower cost and higher reliability. However, multi-phase machines offer advantages when compared to the three-phase counterpart [5], [6]. These advantages are especially interesting for propulsion applications, like moreelectric aircraft [7], EVs [8]-[11], or ship propulsion [12], [13]. Compared to the three-phase counterparts, multi-phase machines offer additional degrees of freedom which can be used for fault-tolerant operation [14]-[16], multi-motor series/parallel-connected drive [17], [18] or torque density

\footnotetext{
Manuscript received Dec. 22, 2010; revised Mar. 15, 2011

Recommended for publication by Guest Associate Editor Byoung-Kuk Lee.

$\dagger$ Corresponding Author: zhaopinzhi@ hit.edu.cn

Tel: +86-451-86415240, Fax: +86-451-86415240, Harbin Institute of Tech.

* Dept. of Electrical Engineering and Automation, Harbin Institute of Technology, China
}

enhancement [19]-[22]. The ability of fault-tolerant operation is very important in life-dependent applications, such as EVs and HEVs. Notice also that the low inverter DC link voltage provided by the battery imposes high-phase currents in the electric drive, making multi-phase drives especially suitable in the EV propulsion systems by means of the lower perphase current. And torque density enhancement ability has shown good prospects for the integration of EV propulsion system. It is based on the principle that the interaction of the spatial and electrical harmonics of the same order can generate a component rotating at fundamental frequency. This component is contributes to positive torque, also providing a flattened magnetic motive force (MMF) shape which is useful to avoid saturation and improve iron utilization.

One of the most interesting multi-phase machines for these applications is the five-phase machine. For five-phase permanent magnetic synchronous motor (FPMSM), this enhancement benefits from the third harmonic air-gap flux, which effectively increases the magnitude of the fundamental flux density, without saturating the machine iron, and the third harmonic component also contributes to positive torque. The quasi-trapezoidal air-gap flux density due to the combination of the two fluxes is essential for torque density enhancement, assuming the same peak air-gap flux density and phase current amplitude. To get this aim, the stator should be wound such that the induced back EMF is quasi- trapezoidal and is supplied by combined sinusoidal and third harmonic current. So this type of FPMSM is called third harmonic injection FPMSM (THI-FPMSM), which benefits from the controllability of PMSM and high torque density of BLDC [23].

Although the principle how THI-FPMSM works has been 
discussed in [24], little literature has been presented relating to determination of windings, permanent magnet steel shapes or third harmonic current injection ratio. This paper aims at improving torque density. Theory basis that third harmonic current generates positive and constant torque is given via deduced mathematic model. The design method for a prototype with quasi-rectangular back EMF and optimization method for third harmonic injection are described. Simulation and experimental results verify the torque density of THI-FPMSM can be enhanced greatly by third harmonic injection.

\section{Modeling OF THI-FPMSM}

The drive system which consists of a five-phase voltage source inverter (VSI) and THI-FPMSM is shown as Fig. 1. The stator winding of THI-FPMSM is connected in star and the neutral point is isolated.

According to amplitude invariant criterion and extended symmetrical component method, the transformation from phase-variable model under natural coordinate system to synchronization rotating coordinate system can be deduced as:

$T(\theta)=\frac{2}{5}\left[\begin{array}{ccccc}\mathrm{c}\left(\theta_{0}\right) & \mathrm{c}\left(\theta_{1}\right) & c\left(\theta_{2}\right) & c\left(\theta_{3}\right) & c\left(\theta_{4}\right) \\ -s\left(\theta_{0}\right) & -s\left(\theta_{1}\right) & -s\left(\theta_{2}\right) & -s\left(\theta_{3}\right) & -s\left(\theta_{4}\right) \\ c\left(3 \theta_{0}\right) & \mathrm{c}\left(3 \theta_{1}\right) & c\left(3 \theta_{2}\right) & c\left(3 \theta_{3}\right) & c\left(3 \theta_{4}\right) \\ -s\left(3 \theta_{0}\right) & -s\left(3 \theta_{1}\right) & -s\left(3 \theta_{2}\right) & -s\left(3 \theta_{3}\right) & -s\left(3 \theta_{4}\right) \\ 1 / 2 & 1 / 2 & 1 / 2 & 1 / 2 & 1 / 2\end{array}\right]$

where, $c(\cdot)$ and $s(\cdot)$ indicate cosine and sine function, respectively. $\theta_{i}=\theta_{r}-i \alpha, \theta_{r}$ denotes angular displacement of rotor, and $\alpha=2 \pi / 5$.

Using the transformation of (1), the $(10 n \pm 1)$ th $(n=1,2$, $3, \ldots)$ harmonics and $(10 n \pm 3)$ th harmonics of five-phase variables are mapped into two orthogonal subspaces which are referred as $d_{1}-q_{1}$ and $d_{3}-q_{3}$ from now on. And the zerosequence component is restrained to zero for star-connected stator winding with isolated neutral point. The $d_{1}-q_{1}$ and $d_{3}$ $q_{3}$ subspaces synchronously rotate at the frequency of $\omega$ and $3 \omega$, respectively. So only the fundamental and third harmonics of five-phase variables can be regarded as DC components, which can contribute to the torque positively [5], [6], [22]. So the mathematic model of THI-FPMSM under orthogonal rotating coordinate system is:

$$
\begin{aligned}
& {\left[\begin{array}{l}
u_{d 1} \\
u_{q 1} \\
u_{d 3} \\
u_{q 3}
\end{array}\right] }=r_{s}\left[\begin{array}{l}
i_{d 1} \\
i_{q 1} \\
i_{d 3} \\
i_{q 3}
\end{array}\right]+\left[\begin{array}{cccc}
L_{d 1} & 0 & L_{13} & 0 \\
0 & L_{q 1} & 0 & L_{13} \\
L_{13} & 0 & L_{d 3} & 0 \\
0 & L_{13} & 0 & L_{q 3}
\end{array}\right] \cdot p\left[\begin{array}{l}
i_{d 1} \\
i_{q 1} \\
i_{d 3} \\
i_{q 3}
\end{array}\right] \\
&+\omega\left[\begin{array}{c}
-L_{q 1} i_{q 1}-L_{13} i_{q 3} \\
L_{d 1} i_{d 1}+L_{13} i_{d 3} \\
-3 L_{13} i_{q 1}-3 L_{q 3} i_{q 3} \\
3 L_{13} i_{d 1}+3 L_{d 3} i_{d 3}
\end{array}\right]+\omega\left[\begin{array}{c}
0 \\
\psi_{\mathrm{m} 1} \\
0 \\
3 \psi_{\mathrm{m} 3}
\end{array}\right]
\end{aligned}
$$

where, $u_{d 1(3)}, \mathrm{u}_{\mathrm{q1}(2)}, i_{d 1(3)}, i_{q 1(3)}$ and $L_{d 1(3)}, L_{q 1(3)}$ are stator voltage, current and inductance in $d_{1}, q_{1}, d_{3}, q_{3}$ axes respectively. $L_{13}$ is mutual inductances of fundamental and third harmonic components induced by influence of salientpole. $r_{s}$ is stator resistance. $\psi_{m} 1$ and $\psi_{m} 3$ are fundamental and third harmonic components of stator flux linkage due to the

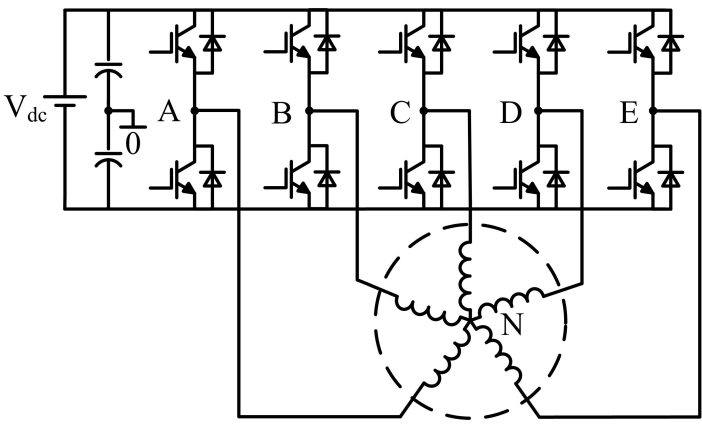

Fig. 1. Structure of five-phase motor and drive system.

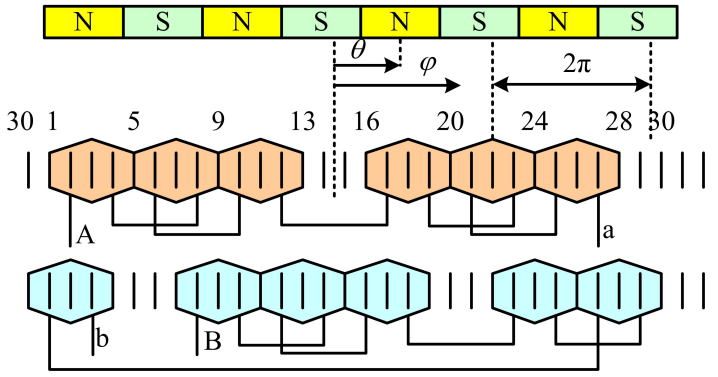

Fig. 2. Winding connections of phase A and B.

permanent magnet. $p$ is the differential operator. For surfacemounted FPMSM, the air-gap can be considered as uniform, so $L_{d 1}=L_{q 1}=L_{1}, L_{d 3}=L_{q 3}=L_{3}$ and $L_{13}=0, d_{1}-q_{1}$ and $d_{3}-q_{3}$ subspaces decouple thoroughly.

For $i_{d 1}=i_{d 3}=0$, the electromagnetic torque can be written as

$$
T=\frac{5 P}{2}\left(\psi_{\mathrm{m} 1} i_{q 1}+3 \psi_{\mathrm{m} 3} i_{q 3}\right)=K_{T 1} i_{q 1}+K_{T 3} i_{q 3}
$$

where, $P$ denotes the number of pole pairs, $K_{T} \equiv 5 \psi_{m 1} / 2$ and $K_{T 3} \equiv 15 \psi_{m 3} / 2$ are torque coefficients of fundamental and third harmonic current respectively.

From (3), it can be seen distinctly, third harmonic component can contribute to the torque positively. That is intrinsic argument for enhancing torque density of THI-FPMSM.

\section{Optimal Design For THI-FPMSM DRIVE}

The induced back electromotive force (EMF) of the motor is a function of the stator winding distribution and air-gap flux, where air-gap flux distribution depends on the magnet dimensions and stator structure. Therefore, it is of significant importance that the proper number of stator slots and winding distribution is chosen.

\section{A. Prototype machine design}

This paper designs an eight-pole FPMSM with five identical quasi-concentrated windings as sketched in Fig. 2, only windings of phase A and B are given here for succinctness. The term of quasi-concentrated is used since each phase winding consists of six fractional slot concentrated winding cells, which are in serial connection. The magnetic steels of rotor are beveled to inject low-order harmonic and constrain high-order harmonic in the air-gap magnetic field.

Winding function of Phase A is shown in Fig. 3, by Fourier analysis, the low order harmonic components can be expressed 


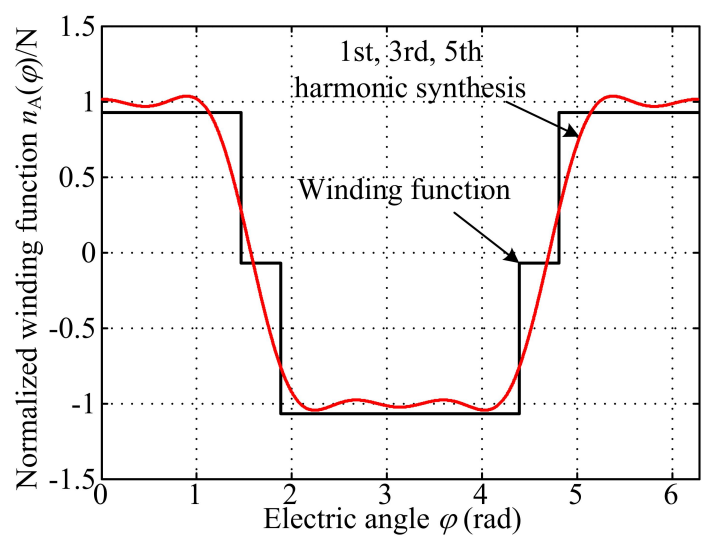

Fig. 3. Normalized winding function and its harmonic synthesis.

as:

$$
n_{\mathrm{A}}(\varphi)=N \sum_{i=1}^{5} k_{w i} \cos (i \varphi)
$$

where, $N$ denotes the number of turns per phase per slot, $k_{w i}$ is the winding factor of $i_{t h}$ harmonic, and $k_{w 1}=1.24, k_{w 2}=$ $-0.12, k_{w 3}=-0.33, k_{w 4}=0.09, k_{w 5}=0.11, \varphi$ represents the angle counterclockwise from the positive A-phase magnetic axis. The even-order components are introduced by the form of fractional slots, but don't effect energy conversion when air-gap magnetic field is symmetrically distributed.

The air-gap flux density function due to the permanent magnet of rotor can be approximated as follows:

$$
b_{\mathrm{m}}=B_{1} \cos (\varphi-\theta)+B_{3} \cos 3(\varphi-\theta)+B_{5} \cos 5(\varphi-\theta)
$$

where, $B_{1}, B_{3}$ and $B_{5}$ are fundamental, third and fifth harmonic components of flux density, and for square wave air-gap flux density whose amplitude is $B, B_{3}=-B_{1} / 3, B_{5}=B_{1} / 5$ and $B_{1}=4 B / \pi$.

From (4) and (5) the flux linkage of the A-phase winding due to the permanent magnet can be obtained as:

$$
\begin{aligned}
\lambda_{\mathrm{Am}} & =r l \int_{-\frac{\pi}{2}}^{\frac{\pi}{2}}\left(N_{\mathrm{A}}(\varphi) b_{\mathrm{m}}\right) d \varphi \\
& =2 r l N \sum_{i=1}^{5} k_{w i} B_{i} \cos (i \theta) \quad i=1,3,5
\end{aligned}
$$

where, $r$ is the air-gap radius, and $l$ is stator length, respectively.

For the star-connected winding, fifth harmonics eliminate each other, so (6) can be simplified as:

$$
\lambda_{A m}=2 r l N\left(k_{w 1} B_{1} \cos \theta+k_{w 3} B_{3} \cos 3 \theta\right)
$$

From (3),

$$
\begin{aligned}
& K_{T 1}=\frac{5 P}{2} \lambda_{m 1}=5 P k_{w 1} r l N B_{1} \\
& K_{T 3}=\frac{15 P}{2} \lambda_{m 3}=15 P k_{w 3} r l N B_{3}
\end{aligned}
$$

For the prototype of this paper, $r=49 \mathrm{~mm}, l=105 \mathrm{~mm}$, $B=0.9 \mathrm{~T}$ and $N=94$,

$$
K_{T 1}=13.7 ; \quad K_{T 3}=3.66 ;
$$

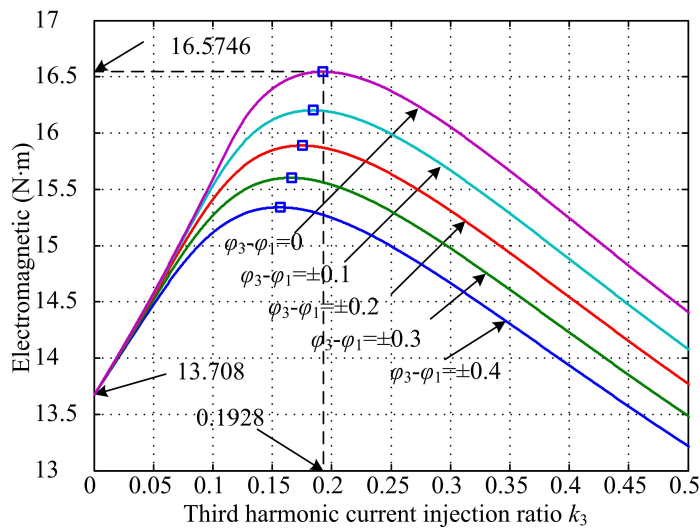

Fig. 4. Optimal design for third harmonic injection ratio.

\section{B. Third harmonic current injection ratio optimization}

Considering the phase current amplitude is restrained by the power capability of inverter, the third harmonic current injection ratio $k_{3}$ must be optimized to maximize the torque density of THI-FPMSM, according to the values of $K_{T 1}$ and $K_{T 3}$. The phase current of phase A can be given as

$$
\begin{gathered}
i_{\mathrm{A} 1}=I_{1} \sin \left(\omega t+\varphi_{1}\right) \\
i_{\mathrm{A} 3}=k_{3} I_{1} \sin \left(3 \omega t+\varphi_{3}\right)
\end{gathered}
$$

where, $I_{1}$ and $I_{3}=k_{3} I_{1}$ are the amplitude values and $\varphi_{1}$ and $\varphi_{3}$ are the phase angles of the fundamental and third harmonic current components respectively.

Assuming the peak value of phase $\mathrm{A}$ is $I_{A}=1$, (10) and (11) must satisfy:

$$
\max \left(i_{\mathrm{A} 1}+i_{\mathrm{A} 3}\right) \leq I_{\mathrm{A}}
$$

According to the theoretical values of $K_{T 1}=13.7$ and $K_{T 3}=$ 3.66 , optimal result can be solved by numerical method. The maximum output torque $(16.5746 \mathrm{~N} \cdot \mathrm{m})$ will be derived when $\varphi_{1}=\varphi_{3}$ and $k_{3}=0.1928$ as shown in Fig. 4. It's obvious that electromagnetic torque is enhanced by $21 \%$, after injecting third harmonic current with optimum ratio.

\section{Dual-Plane Vector Control Method And DIGITAL IMPLEMENTATION}

\section{A. Dual-plane vector control method}

From THI-FPMSM modeling of (2) and (3), it is found that $d_{1}-q_{1}$ and $d_{3}-q_{3}$ subspaces behave as two independent fictitious two-phase machines, sharing the same magnetic structure and mechanical coupling. To obtain the optimum torque density, the optimal design method is proposed in this paper. What's more, fundamental and third harmonic current should be controlled to have the same initial phase and proper ratio of amplitude.

In vector control system of three-phase machines, the current loop is formed of two separate current controllers with PI behavior for the field-forming component $i_{d}$ (comparable with the field current of the DC motor) and the torqueforming component $i_{q}$ (comparable with the armature current of the DC motor). Similarly, the dual-plane vector control system for THI-FPMSM consists of two pairs of current 


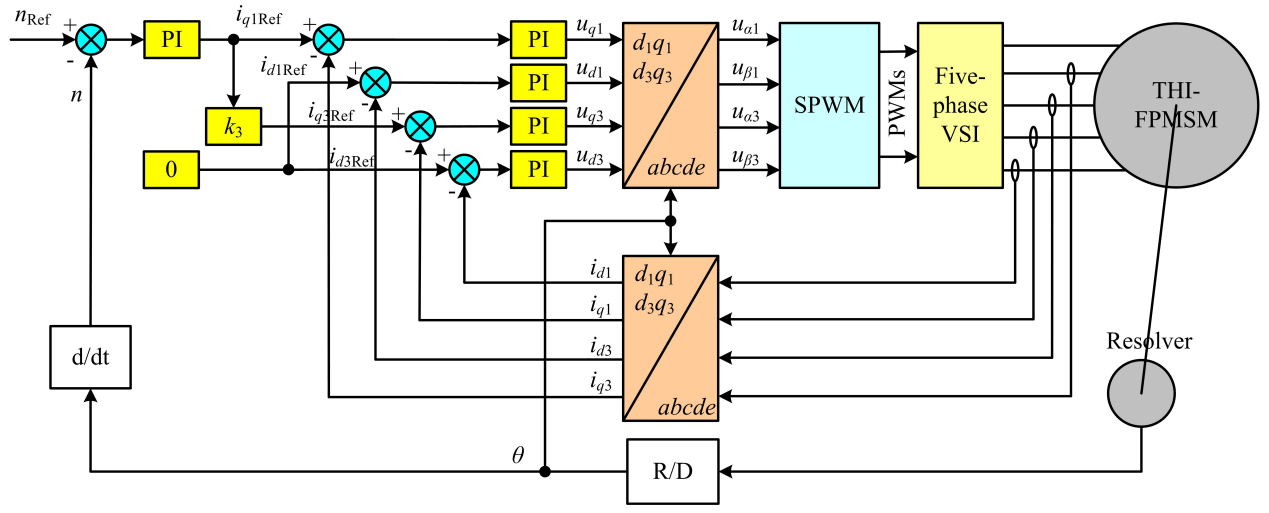

Fig. 5. Dual-plane vector control of THI-FPMSM.

controllers with PI behavior also, each of which operate in the synchronous reference frames determined with the frequency of themselves respectively as shown in Fig. 5. The addition of the second current controller pair enables operation of the drive with expected combination of fundamental and third harmonic currents. The magnitude and rotating speed of each harmonic component are independently controlled. The current reference comes form outer speed loop, and is distributed to two inner current loops in a certain proportion determined by injection ratio $k_{3}$.

\section{B. Digital implement based on FPGA}

Dual-plane vector control is much more complex than traditional vector control of three-phase machine, and demands more computing resource. To overcome degradation of system performance caused by time delay of software processing, the implementation of the proposed controller has been accomplished using FPGA technology. In recent years, FPGA-based hardware implementation technology has been used to motor control systems due to the advantages of their programmable hard-wired feature, fast time-to-market and reusable IP (Intellectual Property) cores. Besides, execution time can be dramatically reduced by designing dedicated parallel architectures by means of hardware mode, allowing FPGA-based controllers to reach the level of performance of their analog counterparts without their drawbacks (parameter drifts, lack of flexibility) [25]-[27].

Fig. 6 shows the internal architecture of the FPGA-based dual-plane vector control IC. The developed control IC consists of four major submodules: a speed controller, two current controllers for fundamental and third harmonic respectively and a five-phase PWM modulator. The data transfers between these elementary operators are managed by a global time sequence controller, which is a finite-state machine (FSM) and synchronized with the system clock signal. The control unit of a module is always activated via a StartPulse signal. When the computation time process is over, an EndPulse element signal indicates to the global controller that the data outputs of the module are ready to be used.

As the execution time of submodules is knowable, it is feasible to control the starting time of sampling circuits, such as $\mathrm{ADC}$ and RDC, to make data more immediate. Besides,

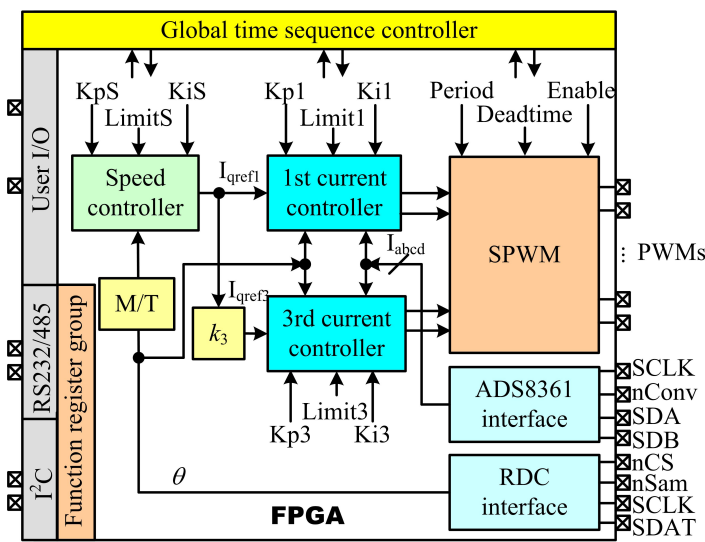

Fig. 6. The internal architecture of FPGA-based dual-plane vector control.

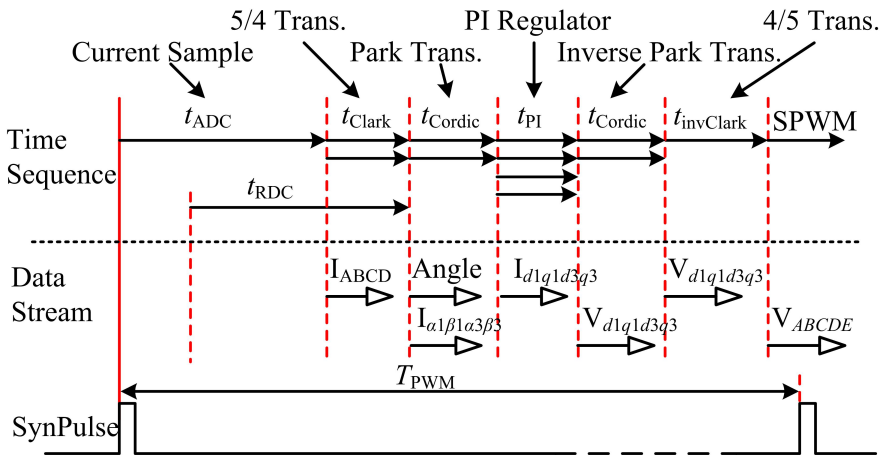

Fig. 7. The timing sequence of dual-plane current control.

some particular modules can be triggered in parallel according to the direction and setup time of data, to shorten the total computation time. The timing sequence of current control loop is given in Fig. 7 as the core of digital controller in Fig. 6. Clark, Cordic and PI submodules are triggered in parallel respectively, and the start time of RDC submodule is set up properly to guarantee that the rotor position information is addressable precisely at the moment Park transformation triggered.

All the submodules are described in Verilog HDL and synthesized using the Xilinx project navigator and support tools. The synthesized Verilog HDL source code is placed, routed and mapped. Finally, a bit file is created. This file is downloaded into the Xilinx XC3S1200E FPGA to interface with peripheral devices. The resources utilization and execu- 
TABLE I

RESOURCES AND EXECUTION TIME OF SubMOdules

\begin{tabular}{|c|c|c|c|c|}
\hline Submodules & Multiplier & Slices & LUTs & Time \\
\hline ADC & 0 & 105 & 42 & $5.2 \mathrm{us}$ \\
5/4 Trans. & 1 & 153 & 175 & $0.6 \mathrm{us}$ \\
Cordic Trans. & 0 & 205 & 404 & $0.6 \mathrm{us}$ \\
4/5 Trans. & 1 & 183 & 245 & $0.48 \mathrm{us}$ \\
PI Regulator & 2 & 85 & 162 & $0.4 \mathrm{us}$ \\
RDC & 1 & 76 & 92 & 4us \\
\hline
\end{tabular}

TABLE II

PARAMETERS OF THI-FPMSM PROTOTYPE

\begin{tabular}{|l|l|l|l|}
\hline Parameter & Value & Parameter & Value \\
\hline$r_{s}(\Omega)$ & 17.5 & $P$ & 4 \\
$L_{m 1}(\mathrm{mH})$ & 44 & $K_{T 1}(\mathrm{~N} \cdot \mathrm{m} / \mathrm{A})$ & $13.7 / 14.1 / 14.16$ \\
$L_{m 3}(\mathrm{mH})$ & 15 & $K_{T 3}(\mathrm{~N} \cdot \mathrm{m} / \mathrm{A})$ & $3.66 / 3.43 / 3.48$ \\
\hline
\end{tabular}

tion time of submodules are shown in TABLE I. The system clock is $25 \mathrm{MHz}$. Execution time is shortened dramatically by adopting single-clock embedded hardware multiplier.

\section{RESUlTS}

\section{A. Two-dimension finite element analysis}

Finite element method is employed to analyze the magnetic field distribution of the proposed THI-FPMSM. Fig. 8 shows the cross section and flux density plots only with the permanent magnet excitation. The flux density is approximately equal under each pole and distribute as quasi-trapezoid. That means the saturation level is identical in most of the iron core. This characteristic is quite helpful for boost the utilization of iron core.

The values of $K_{T 1}$ and $K_{T 3}$ obtained by infinite element method are listed in TABLE II. There is some error between simulation results and theoretical calculated values in (9). This is caused by the assumption of square wave air-gap flux density in (5), while the actual flux density is trapezoidal as shown in Fig. 8.

The third harmonic content is smaller, and the optimum injection ratio is a little different, to be $k_{3}=0.1895$. Maintaining the amplitude of phase current to be $1 \mathrm{~A}$ and phase difference between fundamental and third harmonic current to be zero, the output torque of prototype under different injection ratio is given in Fig. 9. Only when the third harmonic injection ratio is set to the optimum ratio, the output torque will reach its maximum value.

\section{B. Experiment results}

To verify the proposed torque density optimum algorithm for THI-FPMSM, a VSI-drived power conversion system was set up (Fig. 10) and tested. The parameters of the prototype motor are listed in TABLE II, where calculated, emulational and experimental values of $K_{T 1}$ and $K_{T 3}$ are given successively. The switching module used in the five-phase PWM inverter was a $600 \mathrm{~V}, 20 \mathrm{~A}$ rated IGBT manufactured by Infineon Co. During the test, the dead time was set at 2 us to prevent arm shorts. The phase currents were measured by a LA55-P LEM Co. current transducer. The measured phase currents were converted to digital signals, by a $16 \mathrm{bit} \mathrm{A} / \mathrm{D}$ converter, and were sent upto a laptop by RS232 communication port of FPGA controller for further analysis.

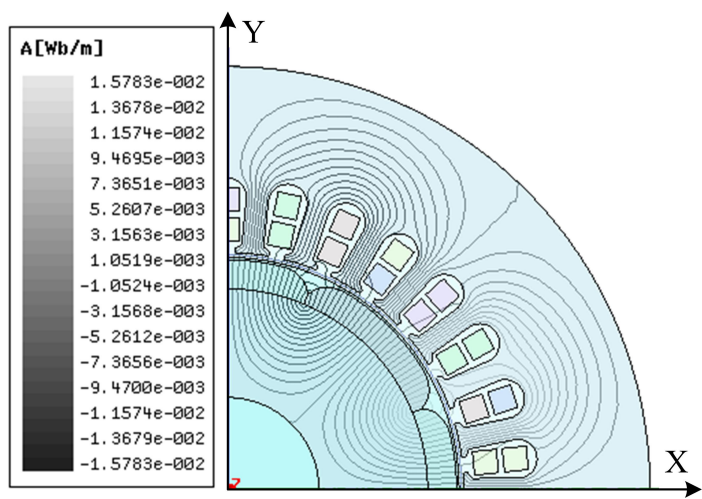

(a) Cross section and magnetic field lines.

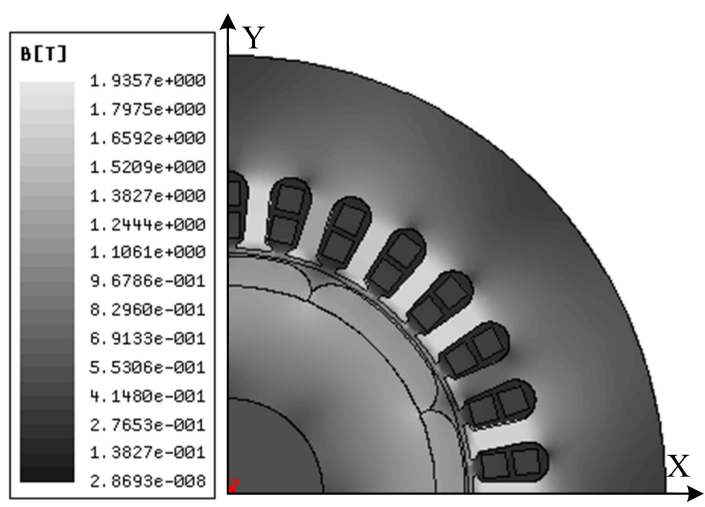

(b) Field flux density nephogram.

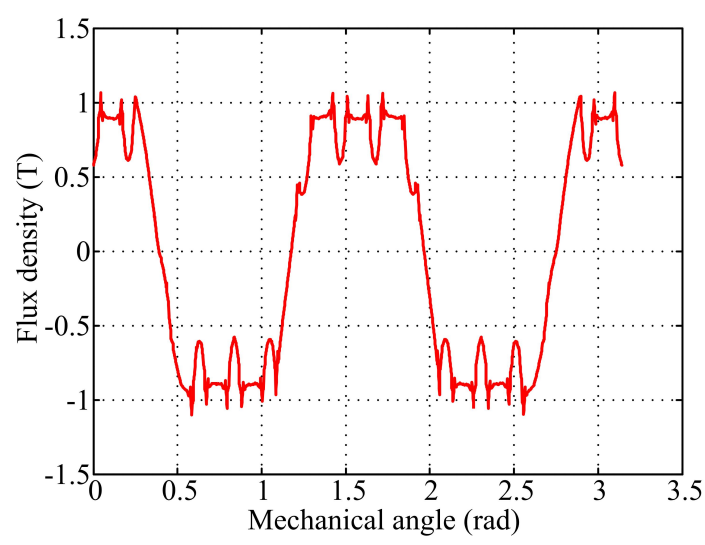

(c) Air-gap flux density normal distribution.

Fig. 8. Cross section and magnetic field distribution with no stator current (one quarter).

The measured back-EMF of prototype is illustrated in Fig. 11.

In Fig. 11(a), the quasi-trapezoidal back-EMF is the phase voltage between terminal and neutral point as shown in Fig. 1. It consists of third and fifth harmonic mainly. In Fig. 11(b), the fifth harmonic is eliminated by a star-connected $10 \mathrm{k} \Omega$ resistance load. It can be calculated that the third harmonic component is $24.3 \%$ of fundamental component.

Fig. 12 shows the currents of phase A and B and loci of current vector under $\alpha_{1}-\beta_{1}$ and $\alpha_{3}-\beta_{3}$ stationary coordinates when $k_{3}=0$ and $k_{3}=0.1895$.

Under this two situations, the amplitude of currents is identical, $1 \mathrm{~A}$, nevertheless the output torque increases from $14.04 \mathrm{~N} \cdot \mathrm{m}$ to $16.9 \mathrm{~N} \cdot \mathrm{m}$, about $20.4 \%$. In Fig. 12(a), there 


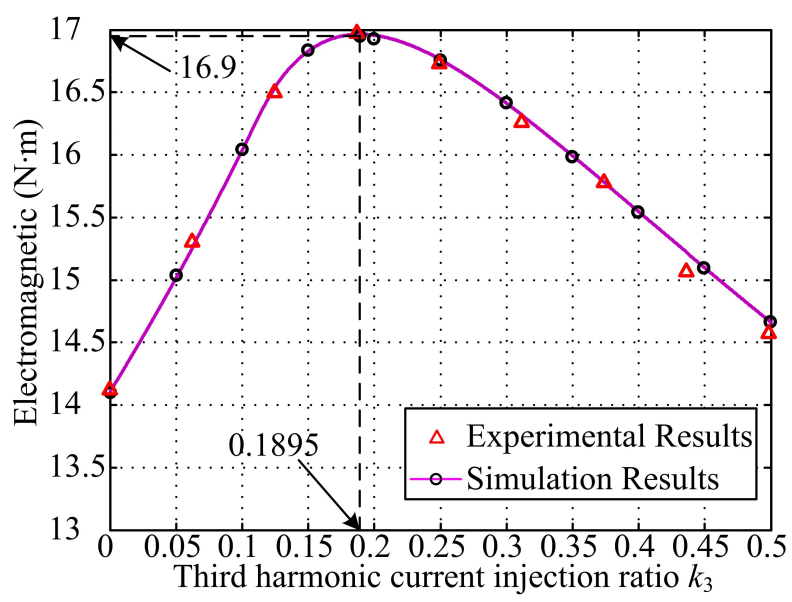

Fig. 9. Relationship of third harmonic injection ratio with electromagnetic torque.

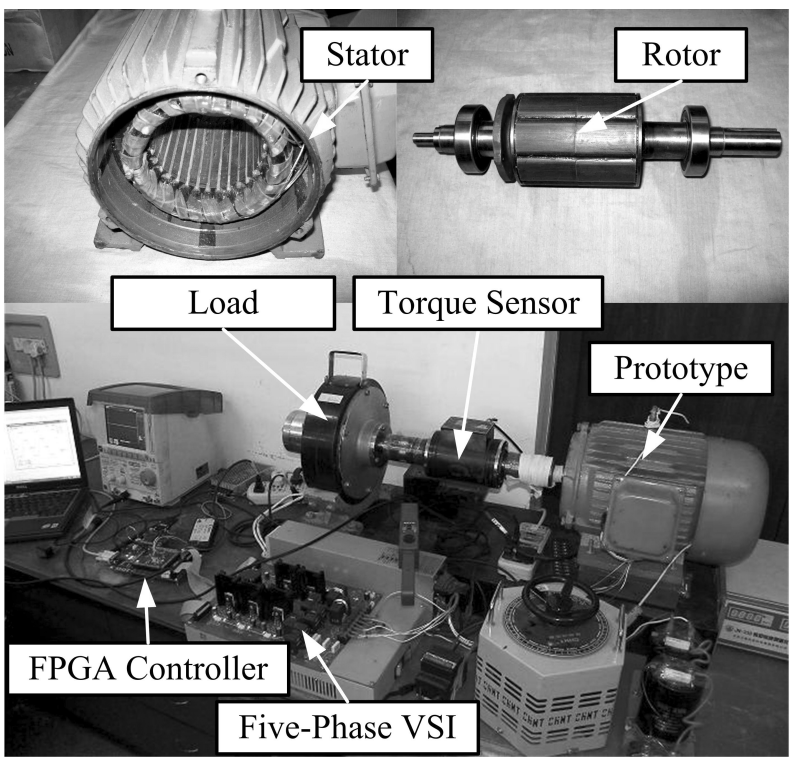

Fig. 10. Photograph of the experimental setup.

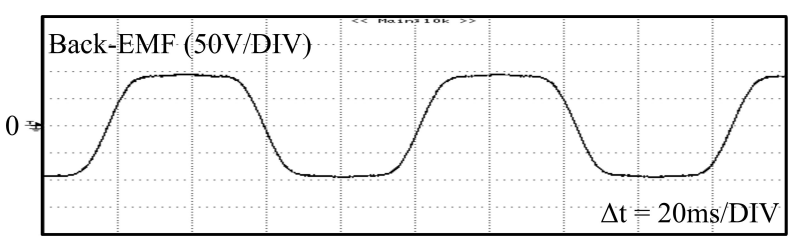

(a) Phase back-EMF

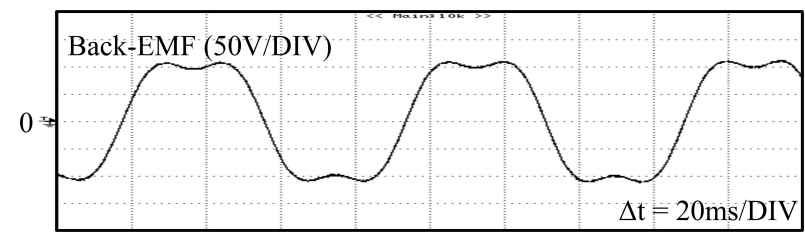

(b) Phase back-EMF eliminating fifth harmonic.

Fig. 11. Measured back-EMF of THI-FPMSM prototype.
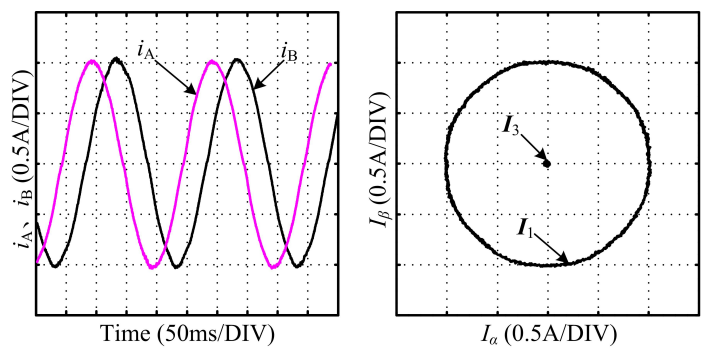

(a)
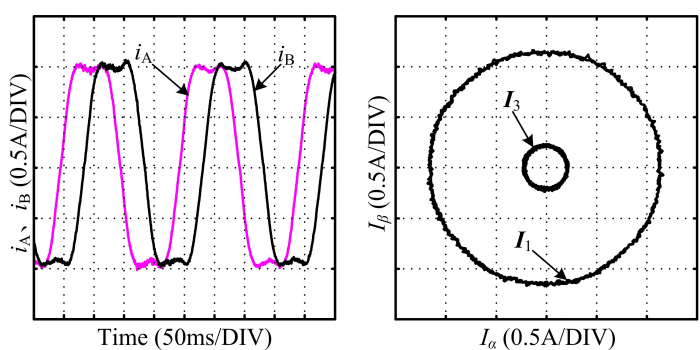

(b)

Fig. 12. Waveforms and loci of current under $\alpha_{1}-\beta_{1}$ and $\alpha_{3}-\beta_{3}$ stationary coordinates when (a) $k_{3}=0$ (b) $k_{3}=0.1895$.

is no injection of third harmonic current, phase currents are sinusoidal. Fundamental current maps into $\alpha_{1}-\beta_{1}$ stationary coordinate as a circular locus whose amplitude is $1 \mathrm{~A}$, while the third harmonic current vector degenerates to a point. In Fig. 12(b), third harmonic current is injected at the ratio of $k_{3}=0.1895$, phase current appears as a saddle-shaped. The amplitude of fundamental current vector increases to $1.16 \mathrm{~A}$, and $0.22 \mathrm{~A}$ for third harmonic current vector. Obviously, torque density can be enhanced by injecting the third harmonic current by proper ratio and phase without increasing current amplitude. The enhancement of torque density benefits from the increase of fundamental current and addition of third harmonic current.

\section{CONCLUSION}

In this paper, the design method for a prototype with quasirectangular back EMF and optimization method for third harmonic are described to enhance the torque density of FPMSM. On the base of multi-dimension characteristic, the interaction of third harmonic field and current can produce constant and positive torque, which is added to the torque generated by fundamental component. By injecting third harmonic field into the sinusoidal rotor field, the peak of fundamental field is clipped. The obtained air-gap flux distributes as quasitrapezoid and is quite helpful for boost the utilization of iron core. Adopting the presented dual-plane vector control method, fundamental and third harmonic components can be controlled effectively and independently to have the same initial phase and proper ratio of amplitude. Under the constrain of identical amplitude and injection of third harmonic current with optimum ratio, the amplitude of fundamental current can be increased by $15 \%$, and so it is to the corresponding torque component. Furthermore, the third harmonic component also produces $5 \%$ increase of torque. So the fundamental and third harmonic components enhance torque density by 20 in together, comparing with sinusoidal situation. 


\section{REFERENCES}

[1] T. Jung, "Development of hybrid electric compressor motor drive system for hybrid electrical vehicles," Journal of Power Electronics, Vol. 9, No. 6, pp. 960-968, Nov. 2009.

[2] C. C. Chan, A. Bouscayrol, and K. Chen, "Electric, hybrid, and fuel-cell vehicles: Architectures and modeling," IEEE Transactions on Vehicular Technology, Vol. 59, No. 2, pp. 589-598, Feb. 2010.

[3] C. C. Chan, "The state of the art of electric, hybrid, and fuel cell vehicles," in Proc. the IEEE, Vol. 95, No. 4, pp. 704-718, 2007.

[4] B. Singh, P. Jain, A. P. Mittal, and J. R. P. Gupta, "Torque ripples minimization of DTC IPMSM drive for the EV propulsion system using a neural network," Journal of Power Electronics, Vol. 8, No. 1, pp. 2334, Jan. 2008

[5] E. Levi, "Multiphase electric machines for variable-speed applications," IEEE Trans. Ind. Electron., Vol. 55, No. 5, pp. 1893-1909, May 2008.

[6] E. Levi, R. Bojoi, F. Profumo, H. A. Toliyat, and S. Williamson, "Multiphase induction motor drives - A technology status review," IET Electric Power Applications, Vol. 1, No .4, pp. 489-516, Jul. 2007.

[7] B. C. Mecrow, A. G. Jack, D. J. Atkinson, S. R. Green, G. J. Atkinson, A. King, and B. Green, "Design and testing of a four-phase faulttolerant permanent-magnet machine for an engine fuel pump," IEEE Trans. Energy Convers., Vol. 19, No. 4, pp. 671-678, Dec. 2004.

[8] J. Riveros, B. Bogado, J. Prieto, F. Barrero, S. Toral, and M. Jones, "Multiphase machines in propulsion drives of electric vehicles," in Proc. Power Electronics and Motion Control Conference (EPE/PEMC), pp. T5-T201, 2010.

[9] M. T. Abolhassani and H. A. Toliyat, "Fault tolerant permanent magnet motor drives for electric vehicles," in Proc. IEEE International Electric Machines and Drives Conference, pp. 1146-1152, 2009.

[10] L. Parsa and H. A. Toliyat, "Fault-tolerant interior-permanent-magnet machines for hybrid electric vehicle applications," IEEE Trans.s Veh. Technol., Vol. 56, No. 4, pp. 1546-1552, Jul. 2007.

[11] M. G. Simoes and P. Vieira Jr, "A high-torque low-speed multiphase brushless machine - A perspective application for electric vehicles," IEEE Trans. on Ind. Electron., Vol. 49, No. 5, pp. 1154-1164, Oct. 2002.

[12] J. Jatskevich and M. Maksimcev, "Dynamic modelling of multiphase induction motors for electric ship propulsion system transient and survivability studies," WSEAS Transactions on Circuits and Systems, Vol. 4, No. 12, pp. 1873-1882, Dec. 2005.

[13] L. Parsa and H. A. Toliyat, "Five-phase permanent magnet motor drives for ship propulsion applications," in Proc. 1st IEEE Electric Ship Technologies Symposium, pp. 371-378, 2005.

[14] Z. Sun, J. Wang, G. W. Jewell, and D. Howe, "Enhanced optimal torque control of fault-tolerant PM machine under flux-weakening operation," IEEE Trans. Ind. Electron., Vol. 57, No. 1, pp. 344-353, Jan. 2010.

[15] N. Bianchi, S. Bolognani, and M. D. Pre, "Impact of stator winding of a five-phase permanent-magnet motor on postfault operations," IEEE Trans. Ind. Electron., Vol. 55, No. 5, pp. 1978-1987, May 2008.

[16] H. M. Ryu, J. W. Kim, and S. K. Sul, "Synchronous frame current control of multi-phase synchronous motor-part ii. asymmetric fault condition due to open phases," in Proc. Conference Record of the IEEE Industry Applications Conference, pp. 268-275, 2004.

[17] M. Jones, S. N. Vukosavic, and E. Levi, "Parallel-connected multiphase multidrive systems with single inverter supply," IEEE Trans. Ind. Electron., Vol. 56, No. 6, pp. 2047-2057, Jun. 2009.
[18] M. R. Khan and A. Iqbal, "Extended Kalman filter based speeds estimation of series-connected five-phase two-motor drive system," Simulation Modelling Practice and Theory, Vol. 17, No. 7, pp. 1346-1360, 2009.

[19] C. C. Scharlau, L. F. A. Pereira, L. A. Pereira, and S. Haffner, "Performance of a five-phase induction machine with optimized air gap field under open loop v/f control," IEEE Trans. on Energy Conversion, Vol. 23, No. 4, pp. 1046-1056, Dec. 2008.

[20] L. Zheng, J. E. Fletcher, B. W. Williams, and X. He, "Dual-plane vector control of a five-phase induction machine for an improved flux pattern," IEEE Trans. Ind. Electron., Vol. 55, No. 5, pp. 1996-2005, May 2008.

[21] M. J. Duran, F. Salas, and M. R. Arahal, "Bifurcation analysis of fivephase induction motor drives with third harmonic injection," IEEE Trans. Ind. Electron., Vol. 55, No. 5, pp. 2006-2014, May 2008.

[22] H. M. Ryu, J. W. Kim, and S. K. Sul, "Synchronous frame current control of multi-phase synchronous motor part I. modeling and current control based on multiple D-Q spaces concept under balanced condition," in Proc. Conference Record of the IEEE Industry Applications Conference, pp. 56-63, 2004.

[23] B. Singh and S. Singh, "State of the art on permanent magnet brushless DC motor drives," Journal of Power Electronics, Vol. 9, No. 1, pp. 1-17, Jan. 2009.

[24] L. Parsa and H. A. Toliyat, "Five-phase permanent-magnet motor drives," IEEE Transactions on Industry Applications, Vol.41, No.1, pp. 30-37, 2005.

[25] M. Naouar, E. Monmasson, A. A. Naassani, I. Slama-Belkhodja, and N. Patin, "FPGA-based current controllers for AC machine drives - A review," IEEE Trans. Ind. Electron., Vol. 54, No. 4, pp. 1907-1925, Aug. 2007.

[26] E. Monmasson and M. N. Cirstea, "FPGA design methodology for industrial control systems - A review," IEEE Trans. Ind. Electron., Vol. 54, No. 4, pp. 1824-1842, Aug. 2007.

[27] R. Arulmozhiyal and K. Baskaran, "Implementation of a fuzzy PI controller for speed control of induction motors using FPGA," Journal of Power Electronics, Vol. 10, No. 1, pp. 65-71, Jan. 2010

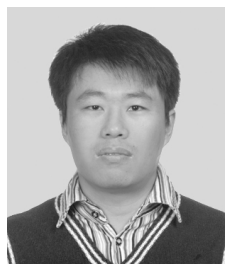

Pinzhi Zhao was born in Hebei Province, China in 1982. He received the B.S. and M.S. degrees in electrical engineering from Harbin Institute of Technology, Harbin, China, in 2005 and 2007, respectively, and is currently working toward Ph.D. degree there. His research interests are power electronics and control, which includes ac machine drives and FPGA based controller.

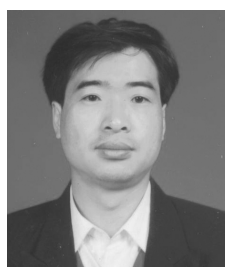

Guijie Yang was born in Heilongjiang Province, China in 1965. He received the B.S. degree in electrical engineering from Harbin University of Science and Technology, Harbin, China, in 1987, and M.S. and Ph.D. degrees in electrical engineering form Harbin Institute of Technology, Harbin, China, in 1992 and 2001, respectively. Since 2004, he has been a Professor with the Department of Electrical Engineering and Automation, Harbin Institute of Technology. His research interests are advanced control of electrical machines and power electronics, multiphase machine drive system, and the use of FPGA for industrial control system. 